Reference Number: DAA-D-13-00025

\title{
BACE1 AS A THERAPEUTIC TARGET IN ALZHEIMER'S DISEASE: RATIONALE AND CURRENT STATUS
}

Genevieve Evin $^{1,2}$ and Christopher Hince ${ }^{1}$

${ }^{1}$ Department of Pathology, The University of Melbourne, Parkville Victoria 3010, Australia, and ${ }^{2}$ Florey Institute of Neuroscience and Mental Health, The University of Melbourne, Parkville Victoria 3010, Australia

Postal Address: $\quad$ Dr Genevieve Evin

Oxidation Biology Laboratory

Florey Institute of Neuroscience and Mental Health

Kenneth Myer Building

30 Royal Parade

The University of Melbourne

Parkville, Victoria 3010, Australia

Email: gmevin@unimelb.edu.au

Running Head: BACE1 as a therapeutic target in Alzheimer's disease 


\begin{abstract}
Alzheimer's disease (AD) is a neurodegenerative disease of the central nervous system, which causes dementia in a large percentage of the aged population and for which there are only symptomatic treatments. Disease-modifying therapies that are currently being pursued are based on the amyloid cascade theory. This states that accumulation of amyloid $\beta(\mathrm{A} \beta)$ in the brain triggers a cascade of cellular events leading to neurodegeneration. $A \beta$, which is the major constituent of amyloid plaques, is a peptidic fragment derived from proteolytic processing of the amyloid precursor protein (APP), by sequential cleavages that involve $\beta$ site APP cleaving enzyme 1 (BACE1) and $\gamma$-secretase. Targeting BACE1 is a rational approach as its cleavage of APP is the rate-limiting step in A $\beta$ production and this enzyme is elevated in the brain of patients with AD. Furthermore, knocking out the BACE1 gene in mice showed little apparent consequences. Ten years of intensive research have lead to the design of efficacious BACE1 inhibitors with favorable pharmacological properties. Several drug candidates have shown promising results in animal models, as they reduce amyloid plaque pathology in the brain and rescue cognitive deficits. Phase I clinical trials indicate that these drugs are well tolerated and the results from further trials in AD patients are now awaited eagerly. Yet, recent novel information on BACE1 biology and the discovery that BACE1 cleaves a selection of substrates involved in myelination, retinal homeostasis, brain circuitry, and synaptic function, alert us to potential side-effects of BACE1 inhibitors that will require further evaluation to provide a safe therapy for AD.
\end{abstract}




\section{Introduction}

Alzheimer's disease (AD) is a neurodegenerative disease of the central nervous system which accounts for $70-80 \%$ cases of dementia and which affects an increasing proportion of the aged population [1]. AD prevalence has steadily risen over the last century to an estimated 25 to 30 million sufferers worldwide, and is set to double by 2030 and more than triple by 2050 [2]. These figures demonstrate the immediate imperative for developing effective $A D$ therapies. This review focuses on recent progress in the development of inhibitors that target the $\beta$-site Amyloid precursor protein Cleaving Enzyme 1 (BACE1) and discusses promises and potential hurdles associated with this therapeutic approach.

\section{The Amyloid Cascade Theory}

Post-mortem histological studies have characterised the presence of senile plaques and intraneuronal tau neurofibrillary tangles as the pathological hallmarks of AD [3]. The identification of the amyloid $\beta$ peptide $(\mathrm{A} \beta)$ as the key constituent of the senile plaques was an important step towards the understanding of AD pathology [4] and fostered a wealth of research into the pathological mechanisms of $A D$, particularly focusing on the role of $A \beta$ in AD pathogenesis. This led to the amyloid cascade hypothesis, which states that the cause of $\mathrm{AD}$ results from an imbalance between $\mathrm{A} \beta$ production and clearance, with the consequent deposition of $A \beta$ plaques causing neuronal dysfunction and death $[5,6]$. Extensive neurodegeneration is considered responsible for the progressive dementia which results in a gradual and severe loss of cognitive function and eventually death [7]. The amyloid cascade hypothesis has been revised over the years $[8,9]$, and it is proposed that $A \beta$ injury may be two-fold. Firstly, the direct toxicity of $A \beta$ oligomers, not the amyloid plaques, would cause injury to the neurons, in particular neuronal synapses. Secondly, this initial insult would trigger downstream effects, which potentially include: neural inflammation, oxidative stress, altered metal ion homeostasis and metal toxicity, as well as altered kinase and phosphatase activity, leading to tau hyperphosphorylation, microtubule dissociation, and the formation of tau neurofibrillary tangles [10]. Although the amyloid cascade hypothesis has been challenged [11, 12], this remains the most widely accepted hypothesis in AD research ant it is supported by compelling genetic evidence that has linked mutations in the amyloid precursor protein and in the presenilins (which are the catalytic subunits of $\gamma$-secretase) to aggressive forms of familial $\mathrm{AD}$, with accelerated production of $\mathrm{A} \beta$ aggregating species [13]. Disappointing results of clinical trials of anti-amyloid therapies may have cast some doubt on 
this approach to $\mathrm{AD}$ treatment but it should be highlighted that such clinical trials were conducted in patients with diagnostically established $\mathrm{AD}$, thus at a stage of advanced neurodegeneration. PET imaging demonstrates $A \beta$ accumulation in the brain of patients at the prodromal stage of the disease [14], well before the first signs of cognitive impairment and 20-30 years before AD clinical onset. Therefore, disease-modifying drugs should be given as an early therapeutic intervention, so as to limit neuronal loss and preserve the brain function.

\section{A $\beta$ Production}

$\mathrm{A} \beta$ is produced through the metabolism of the Amyloid Precursor Protein (APP), a type 1 integral membrane receptor [15], which is involved in the regulation of neuronal activity, synaptic function, and neurogenesis, as well as metal homeostasis [16-19]. A $\beta$ results from the dual cleavage of APP via the amyloidogenic pathway [20]. APP is first cleaved by $\beta$ secretase, to form a large, soluble extracellular fragment (sAPP $\beta$ ) and a small membrane bound amyloidogenic carboxyl terminal fragment of ninety-nine amino acids (C99). The C99 fragment is further processed by $\gamma$-secretase to release the APP intracellular domain (AICD) in the cytosol, and $A \beta$ peptides on the luminal/extra cellular space [21]. Soluble A $\beta$ is thought to undergo further conformational changes, primarily obtaining a $\beta$-sheet conformation which is more prone to aggregation [22]. Alternatively, APP can be processed by a non-amyloidogenic pathway, where it is cleaved by $\alpha$-secretase to produce the soluble extracellular fragment $\alpha(\mathrm{sAPP} \alpha)$ and a non-amyloidogenic C-terminal fragment (C83), which is subsequently cleaved by $\gamma$-secretase to produce a short $\mathrm{p} 3$ peptide and the AICD [20]. As the non-amyloidogenic pathway does not produce $A \beta$, a preference for the amyloidogenic over the non-amyloidogenic APP processing pathway predisposes AD pathology, as illustrated by the recent discovery of a mutation in the APP gene, in Finnish families, which impairs $\beta$-secretase cleavage, lessens $A \beta$ production, and appears to protect its carriers against developing old age dementia [23, 24].

\section{BACE1 Structure and Biology}

BACE1 was identified in 1999 as the enzyme responsible for performing the $\beta$-secretase function, which is defined as the first cleavage step in the production of A $\beta$ from APP (reviewed in [25]). BACE1 is a 501 amino acid, membrane-bound proteolytic enzyme, which represents the prototype of a new subclass of aspartyl proteases, with distinctive structural features and a unique arrangement of disulfide bonds [26-31]. Its crystal structure in complex 
with an inhibitor has revealed an extended catalytic site that confers it with substrate specificity and has provided the bases for developing inhibitors [32]. Another distinct feature of BACE1 is its anchoring in cellular membranes through a C-terminal single transmembrane domain, which restricts its subcellular distribution, and dictates its orientation to facilitate an interaction with membrane-associated substrates, such as APP [26] [33].[21, 34, 35]. BACE1 is synthesized in the endoplasmic reticulum as the proBACE1 precursor, and undergoes extensive post translational modifications, which take place while trafficking through the Golgi. These involve removal of the prosequence by furinn, and complete glycosylation [31, 35-38]. The mature BACE1 is sorted and packaged by clathrin adaptor proteins for export to the endosome, which is an acidic cellular compartment with optimal pH for BACE1 enzymatic activity $[35,39]$. BACE1 can also undergo phosphorylation at C-terminal serine 498, which mediates its retrieval from the plasma membrane to early endosomes under the control of the Golgi-localized, $\gamma$-ear-containing, Arf (ADP-ribosylation factor), GGA adaptor proteins [40-42]. Palmitoylation of cysteines 478, 482 and 485 faciltates its segregation to lipid raft membrane domains [38]. Ubiquitination of lysine 501 is a signal for BACE1 proteosomal degradation and for its recognition by the GGA3 adaptor protein for transport to lysosomal degradation [43] [44, 45]. BACE1 is cycled between the trans-Golgi network, cell surface, and early endosomes, and it is during this cycling that it recruits its APP substrate. Aberrant and continued recycling of BACE1 without degradation due to alterations of sorting proteins that control its cellular turnover, has been linked to increased $\mathrm{A} \beta$ production and $\mathrm{AD}$ $[46,47]$. BACE1 activity can be enhanced by homodimerisation $[48,49]$ and the cellular mechanisms that prompt BACE1 dimer formation remain to be identified.

\section{BACE1 in Alzheimer's Disease}

The finding that a double mutation in APP, which segregates with early-onset AD in a Swedish family, increases BACE1 access to the $\beta$-secretase cleavage site and boosts $A \beta$ production, together with the fact that transgenic mice overexpressing BACE1 have increased brain $\mathrm{A} \beta$ levels support that BACE1 activity plays a significant role in AD pathogenesis [50]. Post-mortem studies have shown that BACE1 protein levels and activity are upregulated in AD brain cortical regions [46, 51-55]. BACE1 activity can be correlated with A $\beta$ deposition in the brain, suggesting an elevation in BACE1 activity is significant in the pathological production of $\mathrm{A} \beta$ [55]. BACE1 increase in $\mathrm{AD}$ brain has been attributed to changes in posttranscriptional and post-translational mechanisms $[46,52,56]$. BACE1 activity is also 
elevated in the cerebrospinal fluid of AD patients [57-61], but its levels may vary at different stages of the disease progression, and this would explain why some researchers have also observed a decrease in BACE1 activity in AD CSF [62]. BACE1 is increased in patients with mild cognitive impairment (MCI), which is the prodromal stage of the illness, and high levels of BACE1 in CSF may help predict conversion from MCI to AD [58]. It also been reported that increased BACE1 activity in MCI patients corelates with change in hippocampal volume and with APOE $\varepsilon 4$ genotype [60].

The event that triggers BACE1 cleavage of APP is yet to be elucidated. Growing experimental evidence from cellular and animal experiments supports that BACE1 is involved in stress response, as increased BACE1 expression was shown to correlate with oxidative stress and aging [63-67], which are key factors in AD onset. The tight control of BACE1 cellular trafficking appears to be the key determinant of its substrate accessibility [43]. Our latest results show that exposing neuronal cultures to non-toxic levels of oxidative stress can prompt the redistribution of BACE1 and enhance its co-localization with APP, hence increase the production of APP amyloidogenic fragments [68].

\section{Pharmacological BACE1 inhibition}

Due to its critical role in AD etiology, BACE1 has attracted much attention for its potential as a therapeutic target $[69,70]$. Initially spurred on by the fact that BACE1 knockout mice showed complete $A \beta$ suppression and no obvious disease phenotype [71] and by the reports that ablation of the $B A C E 1$ gene in $\mathrm{AD}$ transgenic mouse models could rescue memory deficits $[72,73]$, many companies have embarked into BACE1 inhibitor discovery programs and produced compounds with high in vitro potency. BACE1 inhibitors were originally designed from substrate analogues, with a non-hydrolysable bond at the BACE1 cleavage site, such as an hydroxyethylene or an hydroxyethylamine isostere [34]. These have provided high affinity inhibitors, which are effective at low nanomolar concentrations in vitro, but which lack blood-brain-barrier permability due to their extended size that is tailored to occupy the large BACE1 catalytic site. Recent research has yielded potent non-peptidic BACE1 inhibitors through structure-guided drug design and refinement, based on data from co-crytallisation of inhibitors with BACE1 and helped identify new inhibitor cores through in silico screening of chemical libraries (reviewed in [74]). Some of the major challenges researchers have encountered in the developement of BACE1 inhibitors have been i) a lack of selectivity for BACE1 versus other aspartyl proteases such as cathepsin D and BACE2 (with 
the first being involved in general protein catabolism, and the latter possibly being involved in $\mathrm{A} \beta$ degradation); ii) insufficient blood brain barrier permeability, mostly due to a large molecular size and/or efflux by P-glycoprotein, which impairs gastrointestinal absorption as well as capillary delivery to the brain [75-77]; iii) interference with potassium channel subunit, human Ether-à-go-go-Related Gene (hERG), leading to potential cardiac toxicity [78]. These are common problems associated with CNS drug discovery, and thousands of compounds had to be trialled for selecting the best drug candidates.

CTS-21166, which was developed from an hydrxyethylene peptide isostere by Ghosh and Tang's team, with Comentis/Astellas, was among the first BACE1 inhibitors reported to be effective in vivo. This compound was shown to reduce $A \beta$ levels in plasma of laboratory animals [79], and successfully reached Phase I clinical trials, where it demonstrated good tolerance and further showed its ability to reduce plasma $A \beta[80]$. The same research group also described GRL-8234, an hydroxylethylamine isostere peptidomimetic with high potency against BACE1 activity in vitro $\left(\mathrm{K}_{\mathrm{i}}=1.8 \mathrm{nM}\right)$ and in cellular systems $\left(\mathrm{ED}_{50}=0.4-1 \mathrm{nM}\right)$, with good selectivity versus BACE2 (39-fold) and cathepsin D (23-fold), and with demonstrated brain penetration and suitable pharmacological properties [81]. A sustained 12-hour reduction in $A \beta_{40}$ levels was observed in the plasma and brain interstitial fluid of $\operatorname{Tg} 2576 \mathrm{AD}$ mice given the drug by intravenous injection. Chronic administration for six months at a dose of $33.4 \mu \mathrm{g} / \mathrm{g} /$ day through implanted osmotic pumps showed good tolerance and a reduction of plasma $A \beta_{40}$ and $A \beta_{42}$ by $60-80 \%$. Remarkably, cognitive performance tests demonstrated that upon prolonged treatment (5-7.5 months) the inhibitor rescued cognitive decline in the animals that received the drug from the age of 12 months, and this was accompanied by a reduction of brain amyloid plaque load. This study demonstrates that BACE1 inhibition can reduce amyloid deposition in the brain and rescue memory deficits in an animal model, and supports the promise of BACE1 inhibitors for AD therapy.

May et al have reported in detail the encouraging preclinical trials of LY-2811376, a nonpeptidic inhibitor that was designed by Lilly Research Laboratories from a fragment-based screening approach by combining hit structures to maximize occupancy of the BACE1 active site. This compound displayed a good oral bioavailibility and an impressive in vivo efficacy [82]. Dosed to PD-APP mouse model at $10-100 \mathrm{mg} / \mathrm{kg}$, it achieved a dose-dependent reduction of brain $\mathrm{A} \beta$ levels (by 47-68\%), of C99 fragment (by 56-78\%), and of sAPP $\beta$ (by $33-43 \%$ ). Trials in beagle dogs showed this could attenuate A $\beta$ levels in the plasma and CSF, 
by $85 \%$ and $70 \%$, respectively. Clinical administration to healthy volunteers indicated its good tolerability and its sustained effect at reducing A $\beta$ and sAPP $\beta$ in the CSF, with concomitant increase in sAPP $\alpha$ [82]. These data provide a convincing proof-of-concept that BACE1 inhibition can be achieved in human. As the results of preclinical toxicity studies of LY-2811376 in rats showed lipofuscin accumulation and degenerescence in the retina [82], the clinical trials of this drug candidate had to be interrupted. This problem was attributed to an off-target effect of the drug that showed insufficient selectivity over cathepsin D. Lilly researchers have now begun Phase I trials of a new compound, LY-2886721, with expected safer properties.

Several other companies have also brought BACE1 inhibitors into clinical trials. Merck Research Laboratories have screened throusands of molecules, explored new scaffolds with success [83-87], and produced MK-8931 that is undergoing Phase II clinical trials and expected to enter Phase III later this year. Preclinical trials reported at conferences showed that this, or a related compound was effective when given orally to monkeys at a dose of 10 $\mathrm{mg} / \mathrm{kg}$, lowering A $\beta$ levels in the brain and CSF by about $90 \%$. Also, researchers at AstraZeneca have recently described AZD3839 as a clinical drug candidate [88]. This compound, which was designed from fragment-based screening and structure-assisted refinement, proves to be 14-fold selective for BACE1 against BACE2, and more than 1,000-fold over cathepsin $\mathrm{D}$, and to have favourable pharmacological properties. Effective at lowering $A \beta$ in the plasma, brain, and CSF of mouse, guinea pig, and primate models, it has now advanced to Phase I clinical trials. Amgen is also known to have begun clinical trials and reported that AC-3/AMG0683, when given orally to rats at $10 \mathrm{mg} / \mathrm{kg}$ can lower A $\beta$ in the brain and CSF by $73 \%$ and $86 \%$, respectively [89]. And EISAI is conducting clinical trials of its compound, EISAI 2609, which has passed successfully preclinical tests and is now in a Phase II study in subjects with mild cognitive impairment.

\section{Potential adverse effects of BACE1 inhibition}

BACE1 inhibition appears to be generally well tolerated in Phase I clinical trials, which involve short treatment in healthy volunteers, and the clinical therapeutic value of BACE1 inhibitors will soon be determined when Phase II and III have been completed. Whether BACE1 inhibition will really prevent $A \beta$ accumulation may be questioned after the publication of a recent report showing that several BACE1 inhibitors administered to animal models produced the expected reductions of $A \beta_{1-40}$ and $A \beta_{1-42}$ in the CSF, but also enhanced 
production of $A \beta_{5-40}$, suggesting that an alternative processing pathway may take over that of BACE1 to process APP and produce potentially aggregating A $\beta$ peptides [90]. Another strong concern is that BACE1 cleaves substrates, other than APP, which may be important for the maintenance of neurons and synaptic function in aging. The first major BACE1 substrate that was uncovered is neuregulin 1 (NRG1), which is the ligand for ErbB receptor tyrosine kinases. The NRG1 precursor isoforms, type I $\beta 1 \mathrm{a}$ and type III $\beta 1$ a require BACE1 cleavage processing to relase their epidermal-growth factor domain and activate ErbB receptors [91-93]. BACE1 knockout mice show some defects in myelination of the central and peripheral nervous systems [91, 94] that reflect an impairment of NRG1/ErbB4 signaling. NRG1 type III plays an important role during embryonic development as it regulates myelin ensheathment, Schwann cell and oligodendrocyte differentiation, as well as neuronal migration [95]. There is also evidence for its role in the regulation of receptors for the neurotransmitters, $\gamma$-Aminobutyric acid (GABA) and N-methyl-D-aspartate (NMDA) [96, 97]. Notably, NRG1 is a susceptibility gene for schizophrenia and other psychotic disorders, thus tampering with its signaling may have adverse consequences. BACE1 was also shown to regulate the expression of the Disrupted-in-Schizophrenia-1 gene, another schizophrenia sucseptibility gene, which has been linked to the NRG1/ErbB/Akt cascade [98]. Consistently with these findings, Savonenko at al have reported that BACE1 knockout mice have phenotypic changes and behaviour deficits that are reminiscent of schizophrenia and can be rescued by antipsychotic drugs [99]. Although treatment of transgenic mice with BACE1 inhibitor Merck-3 had apparently no effect on NRG1 levels [100], the intricate expression, processing, and biological function of NRG1 in the brain [93] will require further investigation so as to foresee the potential side effects of inhibiting BACE1 processing of NRG1, particularly in aging. Monitoring psychotic symptoms in the patients who will receive BACE1 inhibitor treatment may be recommended. BACE1 also plays an imporrtant role in modulating membrane excitability, as it is involved in the processing of the $\beta$ ( $\beta 1, \beta 2, \beta 3$, and $\beta 4$ ) auxillilary subunits of the $\mathrm{Na}_{\mathrm{v}} 1$ voltage-gated sodium channel (VGSC) [101-103], and of the KCNE1 and KCNE2 subunits of voltage-gated potassium channels [104]. Other BACE1 substrates include the amyloid precursor-like proteins, APLP-1 and APLP-2 [92, 105], the alpha2,6-sialyltransferase, which is involved in liver copper homeostasis [106], the cell-adhesion P-selectin glycoprotein ligand-1 [101], the low density lipoprotein receptor related protein (LRP), which is required for endocytosis and lipid homeostasis [107], and other substrates that are specifically expressed in the brain and are involved in cell adhesion 
and inflammation [108-110]. Indeed, proteomic analyses have revealed among BACE1 substrates, the neural cell adhesion molecules L1 and "close homologue of L1" (CHL1), the Seizure protein 6 homologue (SEZ-6), and contactin-2, which are required for axonal guidance and formation of neuronal circuits during the brain development, and also for the maintenance and regeneration of sensory neurons later in life. Impaired cleavage processing of these substrates and defects in axonal guidance were demonstrated in mice with BACE1 gene knockout and in animals treated with the BACE1 inhibitor LY2811376 [109, 111]. These findings are consistent with the reports of seizures in the $B A C E 1^{-/}$mice $[112,113]$, as well as synaptic deficits $[114,115]$. Retinal pathology is another potential side-effect of BACE1 inhibition that should be followed. Cai et al have recently reported retinal thinning, reduced retinal vascular density, and accumulation of lipofuscin age pigment in $B A C E 1^{-/}$ mice [116]. The authors also demonstrated that BACE1 suppression by siRNA or with a chemical inhibitor caused a dysregulation of retinal angiogenesis, due to the suppression of vascular endothelial growth factor receptor 1 processing [116]. The accumulation of lipofuscin was attributed to a decrease in lysosomal function.

In sum, an increasing number of potential side-effects of BACE1 inhibition will require careful attention. The ethical issues of giving patients BACE1 inhibitors which may have long term negative effects could be questioned, while considering that $\mathrm{AD}$ is an illness that can span ten years or more and which requires a lasting treatment. However, it is important to point out that the data showing toxicity of BACE1 inhibition result from the suppression of BACE1 activity in young animals $[112,113,116]$. The patients to be targeteed with BACE1 inhibitors are elderly individuals with high BACE1 levels, thus it is essential to investigate further the consequences of elevated BACE1 on brain pathology, besides increased $\mathrm{A} \beta$ production, to balance the positive and negative outcomes of BACE1 inhibition. As inflammation, seizures, and hyperexcitability are some features of the AD brain, and these may be driven and exacerbated by BACE1 elevation, BACE1 inhibition might actually offer additional advantages to decreasing $A \beta$ pathology. A recent study shows with an APP transgenic mouse model that high BACE1 levels and increased cleavage of sodium channel $\beta 2$ subunit associate with aberrant neuronal excitability and with cognitive deficits [117]. Therefore, we could assume that a safe therapeutic approach will require establishing the right dosage of BACE1 inhibitors that can restore BACE1 activity to near normal levels, and take care not to decrease it beyond levels that would compromise its normal function. 


\section{Alternative Approaches to Modulating BACE1 Activity}

Besides designing molecules that target the BACE1 active site, other strategies have been explored to modulate BACE1 activity. Such an approach consists in interfering with BACE1 association with cellular membranes using chemical compounds that were identified through cellular screening as capable of modulating $\beta$-secretase cleavage of APP. The compound KMI-574 was proposed to modify BACE1 conformation and molecular associations, and thereby to dislodge the enzyme from lipid rafts, possibly to alter its trafficking, and prevent its interaction with APP [118]. Takeda compound, TAK-070 was also shown to function as a non-competitive inhibitor by presumably binding to the BACE1 transmembrane domain [119]. Oral administration of this compound showed a significant reduction, although modest, in levels of $A \beta_{40}$ and $A \beta_{42}$ in the brain of Tg2576 mice, with concomitant increase in sAPP $\alpha$. Chronic treatment at a dose of $7 \mathrm{mg} / \mathrm{kg} /$ dayfor six months decreased amyloid plaque burden by $\sim 60 \%$. An amelioration in cognitive performance in memory behaviour tests was observed in mice given orally $3 \mathrm{mg} / \mathrm{kg} / \mathrm{day}$, and none of the behavioural phenotypes that were observed by others in the BACE1 knockout animals. These data suggest that achieving a partial reduction in BACE1 activity is sufficient to decrease amyloid load in the brain and rescue cognitive deficits, without noticeable secondary effects.

The use of monoclonal antibodies offers another approach to interfere with BACE1 activity. Zhou et al demonstrated the feasibility of this method by showing that monoclonal antibodies that target BACE1 surface loops can reduce $\mathrm{A} \beta$ secretion from primary neuronal cultures [120]. Direct injection into the brain of APP transgenic mice significantly decreased levels of $\mathrm{A} \beta_{40}, \mathrm{~A} \beta_{42}$, and C99 fragment. Researchers at Genentech also developed a BACE1 monoclonal antibody that targets a surface epitope of the enzyme, and proved its efficacy at inhibiting BACE1 activity and cleavage of APP in cellular systems and animal models, including mice and monkeys [121]. The advantages of this antibody are its excellent selectivity for BACE1 and its ready intracellular delivery, as it becomes endocytosed together with BACE1 after binding the protease at the surface of neurons. Repeated peritoneal injections in Tg2576 mice resulted in $70 \%$ decreases of $A \beta_{1-40}$ and $A \beta_{1-42}$ in the plasma, but reductions of brain $A \beta_{1-40}$ and $A \beta_{1-42}$. were more modest ( 20\%). A reduction of peripheral and CSF $A \beta_{1-40}$ was also demonstrated in primates. To improve brain penetrance, the Genentech researchers designed a bispecific antibody by combining a low affinity transferrin receptor antibody and a BACE1 antibody [122]. 
Methods of RNA interference are also being explored as a means to control BACE1 expression levels. BACE1 suppression by small interfering RNA (siRNA) was demonstrated to inhibit production of $A \beta$ and C99 using primary neural cultures [123] and to ameliorate neuropathology and behaviour in transgenic mice [124]. Injecting lentiviral plasmids expressing BACE1 siRNA into the brain of APP transgenic mice not only decreased BACE1 expression, but also decreased levels of $A \beta_{1-42}$ and APP C99 fragment, and rescued cognitive deficits in spatial memory tests. Improving the methodology for siRNA delivery to the brain is in progress $[125,126]$.

\section{Conclusions}

BACE1 initiates the amyloid cascade and is therefore a very attractive therapeutic target. A panoply of inhibitors and other tools are now available to modulate BACE1 activity. These have proved to be effective in preclinical trials, as these reduce brain amyloid deposition and rescue cognitive deficits in animal models. With recent progress at detecting biomarkers changes in the brain and CSF of patients at the prodromal stage of $\mathrm{AD}$, we may expect that the early administration of BACE1 inhibitors will decrease $A \beta$ formation and prevent $A \beta$ mediated neurodegeneration. However, the function of BACE1 remains to be fully elucidated, in particular the role it plays in the maintenance of neuronal circuits and synaptic activity, in the regulation of retinal homeostasis, and in lysosomal function, so as to anticipate and compensate potential side-effects of BACE1 inhibition.

\section{Acknowledgements}

We acknowledge the funding support from the Judith Jane Mason \& Harold Stannett Williams Memorial Foundation. The authors have no conflict of interest that are directly relevant to the content of this review.

\section{References}

1. Cai J, Qi X, Kociok N, Skosyrski S, Emilio A, Ruan Q, et al. $\beta$-Secretase (BACE1) inhibition causes retinal pathology by vascular dysregulation and accumulation of age pigment. EMBO Mol Med. 2012;4(9):980-91. 
2. World Health Organization and Alzheimer's Disease International. Dementia: a public health priority. Geneva, Switzerland: World Health Organization; 2012.

3. Masters CL, Beyreuther K. Alzheimer's centennial legacy: prospects for rational therapeutic intervention targeting the Abeta amyloid pathway. Brain. 2006;129(Pt 11):282339.

4. Masters CL, Simms G, Weinman NA, Multhaup G, McDonald BL, Beyreuther K. Amyloid plaque core protein in Alzheimer disease and Down syndrome. Proc Natl Acad Sci U S A. $1985 ; 82(12): 4245-9$.

5. Hardy JA, Higgins GA. Alzheimer's disease: the amyloid cascade hypothesis. Science. 1992;256(5054):184-5.

6. Hardy J, Selkoe DJ. The amyloid hypothesis of Alzheimer's disease: progress and problems on the road to therapeutics. Science. 2002;297(5580):353-6.

7. Mayeux R. Epidemiology of neurodegeneration. Annual review of neuroscience. 2003;26:81-104.

8. Hardy J. Testing times for the "amyloid cascade hypothesis". Neurobiol Aging. 2002;23(6):1073-4.

9. Karran E, Mercken M, De Strooper B. The amyloid cascade hypothesis for Alzheimer's disease: an appraisal for the development of therapeutics. Nature reviews Drug discovery. 2011;10(9):698-712.

10. Crouch PJ, Harding SM, White AR, Camakaris J, Bush AI, Masters CL. Mechanisms of A beta mediated neurodegeneration in Alzheimer's disease. Int J Biochem Cell Biol. 2008;40(2):181-98.

11. Armstrong RA. The pathogenesis of Alzheimer's disease: a reevaluation of the "amyloid cascade hypothesis". Int J Alzheimers Dis. 2011;2011:630865.

12. Lee HG, Zhu X, Castellani RJ, Nunomura A, Perry G, Smith MA. Amyloid-beta in Alzheimer disease: the null versus the alternate hypotheses. J Pharmacol Exp Ther. 2007;321(3):823-9.

13. Goate A, Hardy J. Twenty years of Alzheimer's disease-causing mutations. J Neurochem. 2012;120 Suppl 1:3-8.

14. Villemagne VL, Burnham S, Bourgeat P, Brown B, Ellis KA, Salvado O, et al. Amyloid beta deposition, neurodegeneration, and cognitive decline in sporadic Alzheimer's disease: a prospective cohort study. Lancet Neurol. 2013;12(4):357-67.

15. Kang J, Lemaire HG, Unterbeck A, Salbaum JM, Masters CL, Grzeschik KH, et al. The precursor of Alzheimer's disease amyloid A4 protein resembles a cell-surface receptor. Nature. 1987;325(6106):733-6.

16. Lazarov O, Demars MP. All in the Family: How the APPs Regulate Neurogenesis. Front Neurosci. 2012;6.

17. Duce JA, Tsatsanis A, Cater MA, James SA, Robb E, Wikhe K, et al. Iron-export ferroxidase activity of beta-amyloid precursor protein is inhibited by zinc in Alzheimer's disease. Cell. 2010;142(6):857-67.

18. Kohli BM, Pflieger D, Mueller LN, Carbonetti G, Aebersold R, Nitsch RM, et al. Interactome of the amyloid precursor protein APP in brain reveals a protein network involved in synaptic vesicle turnover and a close association with Synaptotagmin-1. J Proteome Res. 2012;11(8):4075-90.

19. Wang Z, Wang B, Yang L, Guo Q, Aithmitti N, Songyang Z, et al. Presynaptic and postsynaptic interaction of the amyloid precursor protein promotes peripheral and central synaptogenesis. J Neurosci. 2009;29(35):10788-801.

20. De Strooper B, Vassar R, Golde T. The secretases: enzymes with therapeutic potential in Alzheimer disease. Nat Rev Neurol. 2010;6(2):99-107. 
21. Creemers JW, Ines Dominguez D, Plets E, Serneels L, Taylor NA, Multhaup G, et al. Processing of beta-secretase by furin and other members of the proprotein convertase family. J Biol Chem. 2001;276(6):4211-7.

22. Fandrich M. Oligomeric intermediates in amyloid formation: structure determination and mechanisms of toxicity. J Mol Biol. 2012;421(4-5):427-40.

23. Jonsson T, Atwal JK, Steinberg S, Snaedal J, Jonsson PV, Bjornsson S, et al. A mutation in APP protects against Alzheimer's disease and age-related cognitive decline. Nature. 2012;488(7409):96-9.

24. Kero M, Paetau A, Polvikoski T, Tanskanen M, Sulkava R, Jansson L, et al. Amyloid precursor protein (APP) A673T mutation in the elderly Finnish population. Neurobiol Aging. 2013;34(5):1518 e1-3.

25. Cole SL, Vassar R. BACE1 structure and function in health and Alzheimer's disease. Curr Alzheimer Res. 2008;5(2):100-20.

26. Sinha S, Anderson JP, Barbour R, Basi GS, Caccavello R, Davis D, et al. Purification and cloning of amyloid precursor protein beta-secretase from human brain. Nature.

1999;402(6761):537-40.

27. Vassar R, Bennett BD, Babu-Khan S, Kahn S, Mendiaz EA, Denis P, et al. Betasecretase cleavage of Alzheimer's amyloid precursor protein by the transmembrane aspartic protease BACE. Science. 1999;286(5440):735-41.

28. Lin X, Koelsch G, Wu S, Downs D, Dashti A, Tang J. Human aspartic protease memapsin 2 cleaves the beta-secretase site of beta-amyloid precursor protein. Proc Natl Acad Sci U S A. 2000;97(4):1456-60.

29. Hussain I, Powell D, Howlett DR, Tew DG, Meek TD, Chapman C, et al. Identification of a novel aspartic protease (Asp 2) as beta-secretase. Mol Cell Neurosci. 1999;14(6):419-27.

30. Yan R, Bienkowski MJ, Shuck ME, Miao H, Tory MC, Pauley AM, et al. Membraneanchored aspartyl protease with Alzheimer's disease beta-secretase activity. Nature. 1999;402(6761):533-7.

31. Haniu M, Denis P, Young Y, Mendiaz EA, Fuller J, Hui JO, et al. Characterization of Alzheimer's beta -secretase protein BACE. A pepsin family member with unusual properties. J Biol Chem. 2000;275(28):21099-106.

32. Hong L, Koelsch G, Lin X, Wu S, Terzyan S, Ghosh AK, et al. Structure of the protease domain of memapsin 2 (beta-secretase) complexed with inhibitor. Science. 2000;290(5489):150-3.

33. Qahwash I, He W, Tomasselli A, Kletzien RF, Yan R. Processing amyloid precursor protein at the beta-site requires proper orientation to be accessed by BACE1. J Biol Chem. 2004;279(37):39010-6.

34. Yan R, Han P, Miao H, Greengard P, Xu H. The transmembrane domain of the Alzheimer's beta-secretase (BACE1) determines its late Golgi localization and access to beta -amyloid precursor protein (APP) substrate. J Biol Chem. 2001;276(39):36788-96.

35. Huse JT, Pijak DS, Leslie GJ, Lee VM, Doms RW. Maturation and endosomal targeting of beta-site amyloid precursor protein-cleaving enzyme. The Alzheimer's disease beta-secretase. J Biol Chem. 2000;275(43):33729-37.

36. Capell A, Steiner H, Willem M, Kaiser H, Meyer C, Walter J, et al. Maturation and pro-peptide cleavage of beta-secretase. J Biol Chem. 2000;275(40):30849-54.

37. Bennett BD, Denis P, Haniu M, Teplow DB, Kahn S, Louis JC, et al. A furin-like convertase mediates propeptide cleavage of BACE, the Alzheimer's beta -secretase. J Biol Chem. 2000;275(48):37712-7.

38. Benjannet S, Elagoz A, Wickham L, Mamarbachi M, Munzer JS, Basak A, et al. Posttranslational processing of beta-secretase (beta-amyloid-converting enzyme) and its 
ectodomain shedding. The pro- and transmembrane/cytosolic domains affect its cellular activity and amyloid-beta production. J Biol Chem. 2001;276(14):10879-87.

39. Kandalepas PC, Vassar R. Identification and biology of beta-secretase. J Neurochem. 2012;120 Suppl 1:55-61.

40. He X, Li F, Chang WP, Tang J. GGA proteins mediate the recycling pathway of memapsin 2 (BACE). J Biol Chem. 2005;280(12):11696-703.

41. He X, Chang WP, Koelsch G, Tang J. Memapsin 2 (beta-secretase) cytosolic domain binds to the VHS domains of GGA1 and GGA2: implications on the endocytosis mechanism of memapsin 2. FEBS Lett. 2002;524(1-3):183-7.

42. von Arnim CA, Tangredi MM, Peltan ID, Lee BM, Irizarry MC, Kinoshita A, et al. Demonstration of BACE (beta-secretase) phosphorylation and its interaction with GGA1 in cells by fluorescence-lifetime imaging microscopy. J Cell Sci. 2004;117(Pt 22):5437-45.

43. Tan J, Evin G. Beta-site APP-cleaving enzyme 1 trafficking and Alzheimer's disease pathogenesis. J Neurochem. 2012;120(6):869-80.

44. Kang EL, Biscaro B, Piazza F, Tesco G. BACE1 endocytosis and trafficking are differentially regulated by ubiquitination at lysine 501 and the di-leucine motif in the $\mathrm{C}$ terminus. J Biol Chem. 2012.

45. Kang EL, Cameron AN, Piazza F, Walker KR, Tesco G. Ubiquitin regulates GGA3mediated degradation of BACE1. J Biol Chem. 2010;285(31):24108-19.

46. Tesco G, Koh YH, Kang EL, Cameron AN, Das S, Sena-Esteves M, et al. Depletion of GGA3 stabilizes BACE and enhances beta-secretase activity. Neuron. 2007;54(5):721-37. 47. Santosa C, Rasche S, Barakat A, Bellingham SA, Ho M, Tan J, et al. Decreased expression of GGA3 protein in Alzheimer's disease frontal cortex and increased codistribution of BACE with the amyloid precursor protein. Neurobiol Dis. 2011;43(1):176-83. 48. Schmechel A, Strauss M, Schlicksupp A, Pipkorn R, Haass C, Bayer TA, et al. Human BACE forms dimers and colocalizes with APP. J Biol Chem. 2004;279(38):39710-7. 49. Westmeyer GG, Willem M, Lichtenthaler SF, Lurman G, Multhaup G, AssfalgMachleidt I, et al. Dimerization of beta-site beta-amyloid precursor protein-cleaving enzyme. J Biol Chem. 2004;279(51):53205-12.

50. Fleck D, Garratt AN, Haass C, Willem M. BACE1 Dependent Neuregulin Proteolysis. Curr Alzheimer Res. 2011.

51. Holsinger RM, McLean CA, Beyreuther K, Masters CL, Evin G. Increased expression of the amyloid precursor beta-secretase in Alzheimer's disease. Ann Neurol. 2002;51(6):7836.

52. Hebert SS, Horre K, Nicolai L, Papadopoulou AS, Mandemakers W, Silahtaroglu AN, et al. Loss of microRNA cluster miR-29a/b-1 in sporadic Alzheimer's disease correlates with increased BACE1/beta-secretase expression. Proc Natl Acad Sci U S A. 2008;105(17):6415-20.

53. Fukumoto H, Cheung BS, Hyman BT, Irizarry MC. Beta-secretase protein and activity are increased in the neocortex in Alzheimer disease. Archives of neurology. 2002;59(9):1381-9.

54. Yang LB, Lindholm K, Yan R, Citron M, Xia W, Yang XL, et al. Elevated betasecretase expression and enzymatic activity detected in sporadic Alzheimer disease. Nat Med. 2003;9(1):3-4.

55. Li R, Lindholm K, Yang LB, Yue X, Citron M, Yan R, et al. Amyloid beta peptide load is correlated with increased beta-secretase activity in sporadic Alzheimer's disease patients. Proc Natl Acad Sci U S A. 2004;101(10):3632-7.

56. Faghihi MA, Modarresi F, Khalil AM, Wood DE, Sahagan BG, Morgan TE, et al. Expression of a noncoding RNA is elevated in Alzheimer's disease and drives rapid feedforward regulation of beta-secretase. Nat Med. 2008;14(7):723-30. 
57. Holsinger RM, McLean CA, Collins SJ, Masters CL, Evin G. Increased betaSecretase activity in cerebrospinal fluid of Alzheimer's disease subjects. Ann Neurol. 2004;55(6):898-9.

58. Zhong Z, Ewers M, Teipel S, Burger K, Wallin A, Blennow K, et al. Levels of betasecretase (BACE1) in cerebrospinal fluid as a predictor of risk in mild cognitive impairment. Arch Gen Psychiatry. 2007;64(6):718-26.

59. Velanac V, Unterbarnscheidt T, Hinrichs W, Gummert MN, Fischer TM, Rossner MJ, et al. Bace1 processing of NRG1 type III produces a myelin-inducing signal but is not essential for the stimulation of myelination. Glia. 2012;60(2):203-17.

60. Ewers M, Cheng X, Nural HF, Walsh C, Meindl T, Teipel SJ, et al. Increased CSFBACE1 Activity Associated with Decreased Hippocampus Volume in Alzheimer's Disease. J Alzheimers Dis. 2010.

61. Holsinger RM, Lee JS, Boyd A, Masters CL, Collins SJ. CSF BACE1 activity is increased in CJD and Alzheimer disease versus [corrected] other dementias. Neurology. 2006;67(4):710-2.

62. Wu G, Sankaranarayanan S, Tugusheva K, Kahana J, Seabrook G, Shi XP, et al. Decrease in age-adjusted cerebrospinal fluid beta-secretase activity in Alzheimer's subjects. Clin Biochem. 2008;41(12):986-96.

63. Tamagno E, Guglielmotto M, Monteleone D, Tabaton M. Amyloid-beta production: major link between oxidative stress and BACE1. Neurotox Res. 2012;22(3):208-19.

64. Chami L, Checler F. BACE1 is at the crossroad of a toxic vicious cycle involving cellular stress and beta-amyloid production in Alzheimer's disease. Mol Neurodegen.

2012;7:52.

65. O'Connor T, Sadleir KR, Maus E, Velliquette RA, Zhao J, Cole SL, et al. Phosphorylation of the translation initiation factor eIF2alpha increases BACE1 levels and promotes amyloidogenesis. Neuron. 2008;60(6):988-1009.

66. Velliquette RA, O'Connor T, Vassar R. Energy inhibition elevates beta-secretase levels and activity and is potentially amyloidogenic in APP transgenic mice: possible early events in Alzheimer's disease pathogenesis. J Neurosci. 2005;25(47):10874-83.

67. Fukumoto H, Rosene DL, Moss MB, Raju S, Hyman BT, Irizarry MC. Beta-secretase activity increases with aging in human, monkey, and mouse brain. Am J Pathol. 2004;164(2):719-25.

68. Tan J, Li QX, Ciccotosto G, Crouch PJ, Culvenor JG, White AR, et al. Mild oxidative stress induces redistribution of BACE1 in non-apoptotic conditions and promotes the amyloidogenic processing of Alzheimer's disease amyloid precursor protein. PLoS One. 2013;8(4):e61246.

69. Evin G, Barakat A, Masters CL. BACE: Therapeutic target and potential biomarker for Alzheimer's disease. Int J Biochem Cell Biol. 2010;42(12):1923-6.

70. Vassar R, Kandalepas PC. The beta-secretase enzyme BACE1 as a therapeutic target for Alzheimer's disease. Alzheimers Res Ther. 2011;3(3):20.

71. Roberds SL, Anderson J, Basi G, Bienkowski MJ, Branstetter DG, Chen KS, et al. BACE knockout mice are healthy despite lacking the primary beta-secretase activity in brain: implications for Alzheimer's disease therapeutics. Hum Mol Genet. 2001;10(12):1317-24. 72. Ohno M, Chang L, Tseng W, Oakley H, Citron M, Klein WL, et al. Temporal memory deficits in Alzheimer's mouse models: rescue by genetic deletion of BACE1. Eur J Neurosci. 2006;23(1):251-60.

73. Ohno M, Cole SL, Yasvoina M, Zhao J, Citron M, Berry R, et al. BACE1 gene deletion prevents neuron loss and memory deficits in 5XFAD APP/PS1 transgenic mice. Neurobiol Dis. 2007;26(1):134-45. 
74. Evin G, Lessene G, Wilkins S. BACE inhibitors as potential drugs for the treatment of Alzheimer's disease: focus on bioactivity. Recent Pat CNS Drug Discov. 2011;6(2):91-106. 75. Weiss MM, Williamson T, Babu-Khan S, Bartberger MD, Brown J, Chen K, et al. Design and preparation of a potent series of hydroxyethylamine containing beta-secretase inhibitors that demonstrate robust reduction of central beta-amyloid. J Med Chem.

2012;55(21):9009-24.

76. Gerritz SW, Zhai W, Shi S, Zhu S, Toyn JH, Meredith JE, Jr., et al. Acyl guanidine inhibitors of beta-secretase (BACE-1): optimization of a micromolar hit to a nanomolar lead via iterative solid- and solution-phase library synthesis. J Med Chem. 2012;55(21):9208-23.

77. Brodney MA, Barreiro G, Ogilvie K, Hajos-Korcsok E, Murray J, Vajdos F, et al. Spirocyclic sulfamides as beta-secretase 1 (BACE-1) inhibitors for the treatment of Alzheimer's disease: utilization of structure based drug design, WaterMap, and CNS penetration studies to identify centrally efficacious inhibitors. J Med Chem. 2012;55(21):9224-39.

78. Swahn BM, Kolmodin K, Karlstrom S, von Berg S, Soderman P, Holenz J, et al. Design and synthesis of beta-site amyloid precursor protein cleaving enzyme (BACE1) inhibitors with in vivo brain reduction of beta-amyloid peptides. J Med Chem.

2012;55(21):9346-61.

79. Ghosh AK, Kumaragurubaran N, Hong L, Kulkarni SS, Xu X, Chang W, et al. Design, synthesis, and X-ray structure of potent memapsin 2 (beta-secretase) inhibitors with isophthalamide derivatives as the P2-P3-ligands. J Med Chem. 2007;50(10):2399-407.

80. Ghosh AK, Brindisi M, Tang J. Developing $\beta$-secretase inhibitors for treatment of Alzheimer's disease. J Neurochem. 2012;120:71-83.

81. Chang WP, Huang X, Downs D, Cirrito JR, Koelsch G, Holtzman DM, et al. Betasecretase inhibitor GRL-8234 rescues age-related cognitive decline in APP transgenic mice. Faseb J. 2011;25(2):775-84.

82. May PC, Dean RA, Lowe SL, Martenyi F, Sheehan SM, Boggs LN, et al. Robust central reduction of amyloid-beta in humans with an orally available, non-peptidic betasecretase inhibitor. J Neurosci. 2011;31(46):16507-16.

83. Stachel SJ, Steele TG, Petrocchi A, Haugabook SJ, McGaughey G, Katharine Holloway M, et al. Discovery of pyrrolidine-based beta-secretase inhibitors: lead advancement through conformational design for maintenance of ligand binding efficiency. Bioorg Medl Chem Lett. 2012;22(1):240-4.

84. Treiber H, Hagemeyer N, Ehrenreich H, Simons M. BACE1 in central nervous system myelination revisited. Mol Psy. 2012;17(3):237-9.

85. Coburn CA, Stachel SJ, Li YM, Rush DM, Steele TG, Chen-Dodson E, et al. Identification of a small molecule nonpeptide active site beta-secretase inhibitor that displays a nontraditional binding mode for aspartyl proteases. J Med Chem. 2004;47(25):6117-9.

86. Steele TG, Hills ID, Nomland AA, de Leon P, Allison T, McGaughey G, et al. Identification of a small molecule beta-secretase inhibitor that binds without catalytic aspartate engagement. Bioorg Med Chem Lett. 2009;19(1):17-20.

87. Mandal M, Zhu Z, Cumming JN, Liu X, Strickland C, Mazzola RD, et al. Design and validation of bicyclic iminopyrimidinones as beta amyloid cleaving enzyme-1 (BACE1) inhibitors: conformational constraint to favor a bioactive conformation. J Med Chem. 2012;55(21):9331-45.

88. Jeppsson F, Eketjall S, Janson J, Karlstrom S, Gustavsson S, Olsson LL, et al. Discovery of AZD3839, a potent and selective BACE1 inhibitor clinical candidate for the treatment of Alzheimer disease. J Biol Chem. 2012;287(49):41245-57.

89. Huang H, La DS, Cheng AC, Whittington DA, Patel VF, Chen K, et al. Structure- and property-based design of aminooxazoline xanthenes as selective, orally efficacious, and CNS 
penetrable BACE inhibitors for the treatment of Alzheimer's disease. J Med Chem. 2012;55(21):9156-69.

90. Mattsson N, Rajendran L, Zetterberg H, Gustavsson M, Andreasson U, Olsson M, et al. BACE1 inhibition induces a specific cerebrospinal fluid beta-amyloid pattern that identifies drug effects in the central nervous system. PLoS One. 2012;7(2):e31084.

91. Willem M, Garratt AN, Novak B, Citron M, Kaufmann S, Rittger A, et al. Control of peripheral nerve myelination by the beta-secretase BACE1. Science. 2006;314(5799):664-6.

92. Li Q, Sudhof TC. Cleavage of amyloid-beta precursor protein and amyloid-beta precursor-like protein by BACE 1. J Biol Chem. 2004;279(11):10542-50.

93. Fleck D, van Bebber F, Colombo A, Galante C, Schwenk BM, Rabe L, et al. Dual Cleavage of Neuregulin 1 Type III by BACE1 and ADAM17 Liberates Its EGF-Like Domain and Allows Paracrine Signaling. J Neurosci. 2013;33(18):7856-69.

94. Hu X, Hicks CW, He W, Wong P, Macklin WB, Trapp BD, et al. Bace1 modulates myelination in the central and peripheral nervous system. Nat Neurosci. 2006;9(12):1520-5. 95. Mei L, Xiong WC. Neuregulin 1 in neural development, synaptic plasticity and schizophrenia. Nat Rev Neurosci. 2008;9(6):437-52.

96. Wen L, Lu Y-S, Zhu X-H, Li X-M, Woo R-S, Chen Y-J, et al. Neuregulin 1 regulates pyramidal neuron activity via ErbB4 in parvalbumin-positive interneurons. Proc Natl Acad Sci U S A. 2009:107(3):1211-6.

97. Pitcher GM, Kalia LV, Ng D, Goodfellow NM, Yee KT, Lambe EK, et al. Schizophrenia susceptibility pathway neuregulin 1-ErbB4 suppresses Src upregulation of NMDA receptors. Nat Med. 2011;17(4):470-8.

98. Seshadri S, Kamiya A, Yokota Y, Prikulis I, Kano S, Hayashi-Takagi A, et al. Disrupted-in-Schizophrenia-1 expression is regulated by beta-site amyloid precursor protein cleaving enzyme-1-neuregulin cascade. Proc Natl Acad Sci U S A. 2010;107(12):5622-7. 99. Savonenko AV, Melnikova T, Laird FM, Stewart KA, Price DL, Wong PC. Alteration of BACE1-dependent NRG1/ErbB4 signaling and schizophrenia-like phenotypes in BACE1null mice. Proc Natl Acad Sci USA. 2008;105(14):5585-90.

100. Sankaranarayanan S, Price EA, Wu G, Crouthamel MC, Shi XP, Tugusheva K, et al. In vivo beta-secretase 1 inhibition leads to brain Abeta lowering and increased alphasecretase processing of amyloid precursor protein without effect on neuregulin-1. J Pharmacol Exp Therapeut. 2008;324(3):957-69.

101. Lichtenthaler SF, Dominguez DI, Westmeyer GG, Reiss K, Haass C, Saftig P, et al. The cell adhesion protein P-selectin glycoprotein ligand-1 is a substrate for the aspartyl protease BACE1. J Biol Chem. 2003;278(49):48713-9.

102. Wong HK, Sakurai T, Oyama F, Kaneko K, Wada K, Miyazaki H, et al. beta Subunits of voltage-gated sodium channels are novel substrates of beta-site amyloid precursor proteincleaving enzyme (BACE1) and gamma-secretase. J Biol Chem. 2005;280(24):23009-17.

103. Dominguez D, Tournoy J, Hartmann D, Huth T, Cryns K, Deforce S, et al. Phenotypic and biochemical analyses of BACE1- and BACE2-deficient mice. J Biol Chem. 2005;280(35):30797-806.

104. Sachse CC, Kim YH, Agsten M, Huth T, Alzheimer C, Kovacs DM, et al. BACE1 and presenilin/gamma-secretase regulate proteolytic processing of KCNE1 and 2, auxiliary subunits of voltage-gated potassium channels. Faseb J. 2013.

105. Eggert S, Paliga K, Soba P, Evin G, Masters CL, Weidemann A, et al. The proteolytic processing of the amyloid precursor protein gene family members APLP-1 and APLP-2 involves alpha-, beta-, gamma-, and epsilon-like cleavages: modulation of APLP-1 processing by n-glycosylation. J Biol Chem. 2004;279(18):18146-56. 
106. Kitazume S, Nakagawa K, Oka R, Tachida Y, Ogawa K, Luo Y, et al. In vivo cleavage of alpha2,6-sialyltransferase by Alzheimer beta-secretase. J Biol Chem. 2005;280(9):8589-95.

107. von Arnim CA, Kinoshita A, Peltan ID, Tangredi MM, Herl L, Lee BM, et al. The low density lipoprotein receptor-related protein (LRP) is a novel beta-secretase (BACE1) substrate. J Biol Chem. 2005;280(18):17777-85.

108. Hemming ML, Elias JE, Gygi SP, Selkoe DJ. Identification of beta-secretase (BACE1) substrates using quantitative proteomics. PLoS One. 2009;4(12):e8477.

109. Kuhn PH, Koroniak K, Hogl S, Colombo A, Zeitschel U, Willem M, et al. Secretome protein enrichment identifies physiological BACE1 protease substrates in neurons. EMBO J. 2012;31(14):3157-68.

110. Zhou L, Barao S, Laga M, Bockstael K, Borgers M, Gijsen H, et al. The neural cell adhesion molecules L1 and CHL1 are cleaved by BACE1 protease in vivo. J Biol Chem. 2012;287(31):25927-40.

111. Hitt B, Riordan SM, Kukreja L, Eimer WA, Rajapaksha TW, Vassar R. beta-Site Amyloid Precursor Protein (APP)-cleaving Enzyme 1 (BACE1)-deficient Mice Exhibit a Close Homolog of L1 (CHL1) Loss-of-function Phenotype Involving Axon Guidance Defects. J Biol Chem. 2012;287(46):38408-25.

112. Hu X, Zhou X, He W, Yang J, Xiong W, Wong P, et al. BACE1 deficiency causes altered neuronal activity and neurodegeneration. J Neurosci. 2010;30(26):8819-29.

113. Hitt BD, Jaramillo TC, Chetkovich DM, Vassar R. BACE1-/- mice exhibit seizure activity that does not correlate with sodium channel level or axonal localization. Mol Neurodegener. 2010;5:31.

114. Laird FM, Cai H, Savonenko AV, Farah MH, He K, Melnikova T, et al. BACE1, a major determinant of selective vulnerability of the brain to amyloid-beta amyloidogenesis, is essential for cognitive, emotional, and synaptic functions. J Neurosci. 2005;25(50):11693709 .

115. Wang H, Song L, Laird F, Wong PC, Lee HK. BACE1 knock-outs display deficits in activity-dependent potentiation of synaptic transmission at mossy fiber to CA3 synapses in the hippocampus. J Neurosci. 2008;28(35):8677-81.

116. Cai J, Qi X, Kociok N, Skosyrski S, Emilio A, Ruan Q, et al. beta-Secretase (BACE1) inhibition causes retinal pathology by vascular dysregulation and accumulation of age pigment. EMBO Mol Med. 2012;4(9):980-91.

117. Corbett BF, Leiser SC, Ling H-P, Nagy R, Breysse N, Zhang X, et al. Sodium Channel Cleavage Is Associated with Aberrant Neuronal Activity and Cognitive Deficits in a Mouse Model of Alzheimer's Disease. J Neurosci. 2013;33(16):7020-6.

118. Hemming ML, Elias JE, Gygi SP, Selkoe DJ. Proteomic profiling of gamma-secretase substrates and mapping of substrate requirements. PLoS Biol. 2008;6(10):e257.

119. Fukumoto H, Takahashi H, Tarui N, Matsui J, Tomita T, Hirode M, et al. A noncompetitive BACE1 inhibitor TAK-070 ameliorates Abeta pathology and behavioral deficits in a mouse model of Alzheimer's disease. J Neurosci. 2010;30(33):11157-66.

120. Zhou L, Chavez-Gutierrez L, Bockstael K, Sannerud R, Annaert W, May PC, et al. Inhibition of beta-secretase in vivo via antibody binding to unique loops (D and F) of BACE1. J Biol Chem. 2011;286(10):8677-87.

121. Atwal JK, Chen Y, Chiu C, Mortensen DL, Meilandt WJ, Liu Y, et al. A therapeutic antibody targeting BACE1 inhibits amyloid-beta production in vivo. Sci Transl Med.

2011;3(84):84ra43.

122. Yu YJ, Zhang Y, Kenrick M, Hoyte K, Luk W, Lu Y, et al. Boosting brain uptake of a therapeutic antibody by reducing its affinity for a transcytosis target. Sci Transl Med.

2011;3(84):84ra44. 
123. Kao SC, Krichevsky AM, Kosik KS, Tsai LH. BACE1 suppression by RNA interference in primary cortical neurons. J Biol Chem. 2004;279(3):1942-9.

124. Singer O, Marr RA, Rockenstein E, Crews L, Coufal NG, Gage FH, et al. Targeting BACE1 with siRNAs ameliorates Alzheimer disease neuropathology in a transgenic model. Nat Neurosci. 2005;8(10):1343-9.

125. Peng KA, Masliah E. Lentivirus-expressed siRNA vectors against Alzheimer disease. Methods Mol Biol. 2010;614:215-24.

126. Alvarez-Erviti L, Seow Y, Yin H, Betts C, Lakhal S, Wood MJ. Delivery of siRNA to the mouse brain by systemic injection of targeted exosomes. Nat Biotech. 2011;29(4):341-5.

\section{Figure Legend}

\section{Figure 1. Secretase Processing of the Amyloid Precursor Protein}

The amyloid precursor protein (APP) in a type I membrane protein, with a large extracellular domain (ectodomain), a transmembrane domain, and a short cytoplasmic domain. The ectodomain can be secreted through two alternative pathways. In the amyloidogenic pathway, cleavage by $\beta$-site APP cleaving enzyme 1 (BACE1) releases the soluble APP N-terminal fragment (sAPP $\beta$ ), thereby producing a membrane-tethered C-terminal fragment of ninetynine amino acids (C99), which is the direct precursor to A $\beta$. C99 is further processed by $\gamma$ secretase $(\gamma$-sec) to produce A $\beta$ and release the APP intracellular domain (AICD) in the cytosol. A $\beta$ self-aggregates to form toxic oligomers that trigger degeneration of neuronal cells. In the non-amyloidogenic pathway, APP is cleaved by $\alpha$-secretase $(\alpha-\mathrm{sec})$, which produces the soluble sAPP $\alpha$ N-terminal fragment and a membrane-tethered, eighty-three amino acid-long $\mathrm{C}$-terminal fragment (C83). $\alpha$-Secretase cleavage occurs within the A $\beta$ domain and precludes $\mathrm{A} \beta$ amyloid formation. C83 is further processed by $\gamma$-secretase to produce the $3 \mathrm{kDa}$, non-amyloidogenic peptide, $\mathrm{p} 3$, and release AICD. 


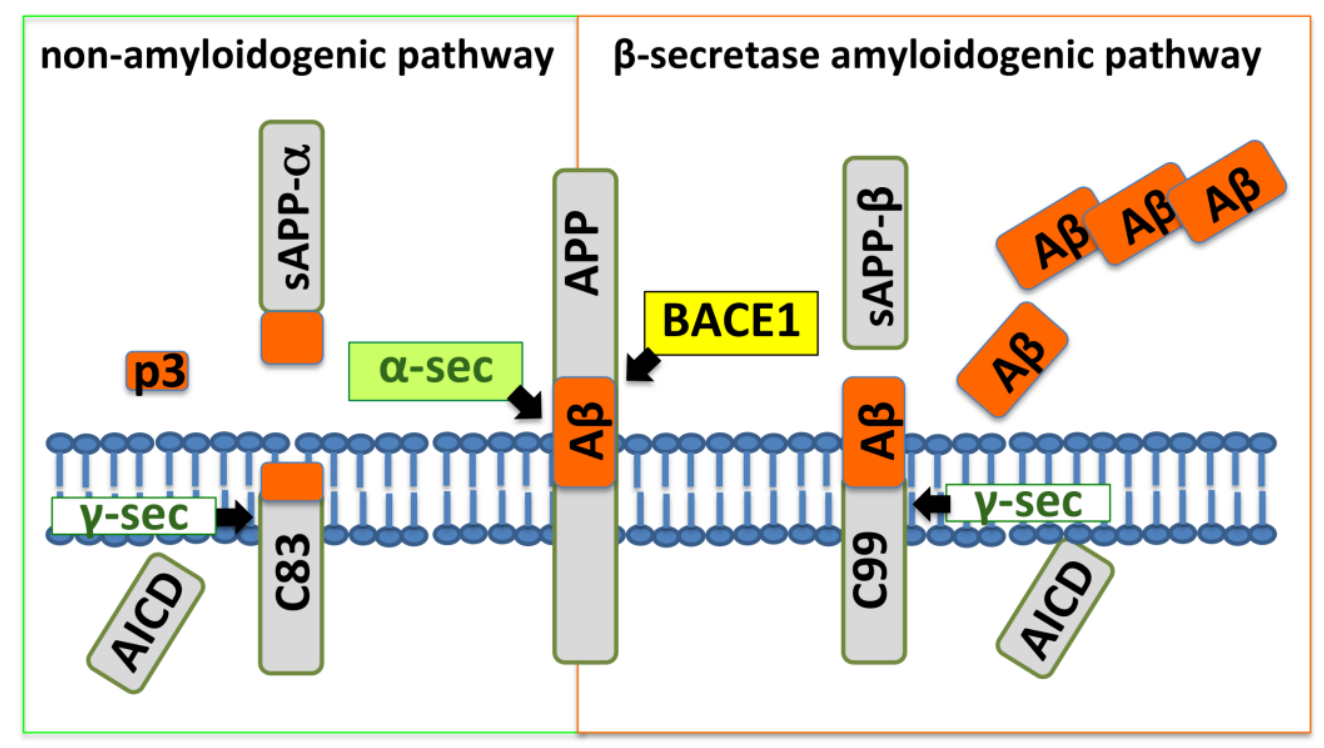

